\title{
Exploration and Practice of Participatory Teaching in College Students' Mental Health Education
}

\author{
Yu Yan \\ Student Affairs Department, Jingjiang College of Jiangsu University, Zhenjiang, China \\ Email address: \\ 31624853@qq.com \\ To cite this article: \\ Yu Yan. Exploration and Practice of Participatory Teaching in College Students' Mental Health Education. Education Journal. \\ Vol. 10, No. 2, 2021, pp. 68-73. doi: 10.11648/j.edu.20211002.16
}

Received: April 7, 2021; Accepted: April 19, 2021; Published: April 29, 2021

\begin{abstract}
Strengthening college students' mental health education is an important content of comprehensively promoting quality-oriented education, an important segment of cultivating high-quality talents, and an important task of strengthening and improving college students' ideological education. Developing mental health education for college students has become one of the deepening educational work in recent years. The class of mental health education is the main way of mental health education in colleges and universities. In order to play its role, it is necessary to think about the teaching content, teaching methods and teaching approaches based on the growth rules and ideological characteristics of college students and the actual needs of students. On the basis of studying the characteristics of college students' mental health education course, we adopted participatory teaching. Involving students in setting teaching objectives, preparing lessons, enriching teaching resources, participating in the teaching process and teaching evaluation can enhance the subjectivity of students, meet the students' diverse needs, help to improve students' learning state and enhance their psychological quality. This paper elaborates the application of participatory teaching in college students' mental health education class, analyzes in depth how to carry out teaching and the precautions in teaching, and probes into the guarantee conditions for participatory teaching to play its role in college students' mental health education.
\end{abstract}

Keywords: Participatory Teaching, Mental Health Education, College Students

\section{Introduction}

"The Outline of National Medium- and Long-term Education Reform and Development Plan" (2010-2020) puts forward the strategic theme of insisting on people-oriented and comprehensive implementation of quality education, and requires adhering to the unity of comprehensive development and personality development, strengthening psychological education and promoting mental health. At present, all colleges and universities have opened the course "Mental Health Education for College Students", which has a very important role in improving college students' mental health care and psychological crisis prevention, promoting their overall development and cultivating their personality. The survey shows that college students have high expectations for mental health education. However, due to the traditional teaching methods, the classroom atmosphere is dull, and the teaching mainly focuses on explaining concepts and expatiating problems, which reduces students' interest in learning and results in poor teaching effect. In this case, participatory teaching has been taken for granted in the curriculum.

\section{The Significance of Participatory Teaching in "Mental Health Education for College Students"}

\subsection{The Essence of Participatory Teaching}

Participatory teaching method originated in the 1950s in Britain, which is a kind of collaborative or cooperative teaching method, advocating learner-centered, equal participation of teachers and students in the learning process, research, analysis and problem-solving methods and approaches [1], focusing on the construction of teacher-student relationship and good learning atmosphere, as well as the cultivation of students' learning habits [2]. 


\subsection{The Necessity of Participatory Teaching}

Compared with other courses, "Mental Health Education for College Students" is a course for all students, regardless of their professional backgrounds, and is different from professional psychology courses. Its main task is to give students the basic theoretical knowledge of mental health and the basic skills of psychological adjustment, so that students can establish a scientific view of mental health and the basic methods and skills of self-adjustment. Therefore, it is necessary to combine classroom education with students' reality, select typical materials from students' real life, and help students solve various conflicts and problems they encounter in the process of growing up through creating situations and case studies, so as to achieve the effect of empathy and introspection. By using participatory teaching methods in the teaching process, teachers and students respect each other and promote each other, constantly interact, carry on dialogues, communicate and share, which is conducive to improving students' self-confidence and psychological adjustment ability.

\subsection{Advantages of Applying Participatory Teaching}

\subsubsection{Improving the Subjectivity of Students}

The course "Mental Health Education for College Students" is a development-oriented quality education, which aims at strengthening students' understanding of themselves, correctly understanding difficulties and setbacks, improving their psychological quality and promoting healthy personality development. The use of participatory teaching methods in this course can stimulate students' interest in learning and make them participate actively.

\subsubsection{Strengthening the Cooperation Between Teachers and Students}

Teaching reform is first of all a revolution in teaching philosophy. Under the participatory teaching mode, teachers are the providers and instructors of learning resources, developers of students' potential, evaluators of learning effects, as well as learners and participants. Teachers and students constantly carry out dialogues, communicate and share with each other, and in the process of interactive experience, teachers play the role of facilitators, thus playing the effect of knowledge transfer and internalization [3].

\subsubsection{Meeting the Students' Diverse Needs}

The age differences and personal differences of different students affect their psychological needs. At the same time, the expression form of psychological needs is diversified, and college students often express their inner demands by verbal communication, textual elaboration, and behavioral implication. Therefore, the establishment of a targeted, classified, hierarchical and differentiated curriculum can truly meet the different needs of different students [4].

\subsubsection{Enriching the form of Classroom Teaching}

Traditional courses often use teachers' lectures as the main focus, while participatory teaching is student-centered, emphasizing students' experiences and feelings, integrating knowledge and principles into interactive activities, situational performances and group discussions, allowing students to learn actively and discover their potential in interactive experiences, so as to improve themselves. At present, many college students' mental health education classes have adopted group discussions, debates and psychodramas for participatory education.

\subsubsection{Cultivating Students' Good Psychological Quality}

The open, good and democratic atmosphere and teaching environment in the participatory teaching classroom, where teachers and students are equal, trust and understand each other, and get along with each other in a friendly manner, helps to enhance students' self-confidence. Through group discussions, students learn to encourage students around them, learn to praise others, and improve their interpersonal skills. The mini-games and mental training conducted in the classroom help students understand themselves, know themselves, discover their shortcomings, improve their psychological quality and promote personality improvement. Under the contextual teaching approach, students participate in psychodramas and can learn to analyze problems, respond to them correctly, and learn to strengthen their psychological regulation in difficult situations and under pressure.

\section{The Dilemma Facing the Mental Health Education Class for College Students}

Many teachers equate the mental health education class with the theoretical teaching class, taking a large number of concepts, theories and principles as the main content of teaching. Therefore, students cannot be taught according to their aptitude and their differences, and then teachers cannot solve the students' confusion in reality. At the same time, the course is boring and the teaching effect is not good. Many teachers adopt "interactive teaching", "inspirational teaching", "case teaching", "role play" and other diversified ways to improve the classroom effect. Although this has enriched the way of classroom teaching, it has also brought new difficulties [5].

First of all, due to the shortage of psychological teachers, mental health education classes are usually arranged as optional courses with about 20 class hours and class size of about 120 students. Using a variety of teaching methods in a small number of hours of mental health education classes places greater pressure on teachers to manage the classroom and allocate time [6]. Even if participatory teaching is incorporated, using heuristics, discussion methods, psychodrama, etc., the class size is too large, resulting in insufficient participation in the activities and affecting enthusiasm for learning.

Secondly, to ensure the objectivity of course evaluation, instructors often fix participatory teaching methods, such as group discussions, keynote speeches, psychodrama 
performances, short psychological videos, and investigation reports. When the participatory teaching methods are fixed, some students in the class cannot participate and cannot get the opportunity to show themselves, which is not conducive to students to express their understanding [7]. Only by allowing students to freely choose and participate in the teaching process can their subjective initiative be brought into play.

Thirdly, the teachers mainly focused on the teaching plan before the class, paying more attention to general issues, but less on students' individual problems and interest, which made the class less participatory.

Fourthly, in the practical teaching, many students have presented their opinions through videos, psychodramas and speeches, reflecting from various angles the psychological confusion faced by college students in the areas of study adaptation, interpersonal communication, emotion and stress resistance and their self-adjustment [8]. If the students' works can be further instructed and refined, it will undoubtedly be a very good teaching case and will inspire more students to create. But at present, there is less work in this field.

\section{Exploration of Participatory Teaching Program for College Students' Mental Health Education}

The research was carried out through a combination of interview survey and questionnaire, aiming to understand the realistic background of carrying out participatory teaching design, the demand for participatory teaching design by teachers, students and other relevant personnel in actual teaching, to grasp the knowledge and attitude of relevant personnel towards participatory teaching design, and to clarify the difficulties faced by participatory teaching design, etc.

The interview mainly includes the awareness of the necessity and feasibility of participatory teaching design, the ideas and opinions on how to carry out participatory teaching design, the awareness and opinions on the difficulties that teachers may encounter in carrying out participatory teaching design, the understanding of and opinions on the possible effectiveness of participatory teaching design and the possible impact, and the opinions and suggestions on carrying out participatory teaching design. The target group of the questionnaire survey selected the junior students who would receive mental health education, including respectively 400 students in the first and second college year. 800 questionnaires were distributed and 758 questionnaires were collected, of which 635 were valid, with an effective recovery rate of $79.38 \%$.

After the comprehensive interview survey and questionnaire survey, the following conclusions were drawn: (1) Students agree very much with the necessity of mental health education for college students and have a certain demand to carry out participatory teaching; (2) Students hope to determine the content of participatory teaching through consultation with teachers; (3) The difficulties faced by participatory teaching include the external environment such as the large number of students in the classroom and the constraints, as well as the problems of teachers and students inside the classroom. The research found that these difficulties are not enough to prevent the development of participatory teaching. According to the existing hardware conditions and staffing, participatory teaching can be carried out with proper measures and methods by making corresponding adjustments and taking appropriate measures.

\section{Design of Participatory Teaching Program of Mental Health Education for College Students}

Stage 1: Understanding the students' needs through research

Only the teaching design close to students' needs can attract and help students. Students should first clarify their own interest, ability and learning needs. At the same time, the teacher should grasp the teaching environment, teaching conditions, teaching contents, and the overall situation of students, and analyze them, then think about the teaching design and find the suitable point between teachers and students. As "Mental Health Education for College Students" is a public optional course, and students come from different majors, so there are several ways to understand the actual needs of students: (1) Students' self-presentation. Students can present their interests, personality traits and learning needs to the teacher in written or oral form in class, which is the most direct way, but time-consuming when there are more students. (2) Teacher-student conversation to understand the situation. Groups are divided and student representatives are selected to learn about the interest and practical needs of the group members and give feedback to the teacher. This method allows the teacher to have a better understanding of the students in the classroom, but it takes a longer time. (3) Questionnaire. It is more convenient for the teacher and students to collaborate in designing a basic situation questionnaire to understand the students' situation and learning needs through the questions listed in the questionnaire.

Stage 2: Teacher-student discussion of the teaching plan

After understanding students' needs, students in the class who are interested in participatory teaching are selected to participate in the instructional design. Firstly, students should be informed of the nature and characteristics of participatory teaching design, and the purpose to be achieved by participatory teaching design should be clarified; then the rules of activities of participatory teaching design should be established with students, and the work and tasks that teachers and students need to be responsible for respectively should be clarified. When teachers and students negotiate and discuss the teaching plan, teachers should create a classroom atmosphere of active participation, stimulate students' enthusiasm for participation, give them guidance on the methods of participation and build their confidence. The work 
at this stage is trivial and messy, but it is a prerequisite and foundation for good participatory teaching. It needs to be considered comprehensively and systematically, with room for flexibility in planning.

Stage 3: Teachers and students negotiating and designing the teaching plan

A lot of ideas and opinions have been generated in the stage of discussing teaching programs. The task of the design stage is to summarize and synthesize these ideas and opinions as well as the preliminary plan, make overall planning and conception of teaching, determine teaching objectives, select teaching contents, and design teaching methods and strategies. Teachers should respect students' suggestions and opinions, and design teaching programs that meet students' individual characteristics, interest and hobbies. The teacher could take the form of flipped classroom and will act as an advisor to the students, and the students will improve the teaching plan according to the teacher's suggestions, and then the final draft will be submitted for implementation [9]. During the "flipped classroom" process, students actively participate in the design of activities, demonstrations, discussions and role plays, and experience, learn and improve through participation.

Stage 4: Implementation of Participatory Teaching

The prerequisite for effective implementation of participatory education is to create a good teaching atmosphere. Before each lesson, teachers can play some small games, such as "finger exercises", to liven up the classroom atmosphere.

In the teaching process, teachers should do the following two things: first, create an equal, harmonious and pleasant environment, without value evaluation and measurement, and slowly dissolve the barriers in a frank and friendly atmosphere, so that each student can easily participate. Second, give active, unconditional attention to and respect for each student, have equal communication with students, accept their individuality and diversity, and create a classroom atmosphere of full trust and rapport.

In the process of participatory teaching, teachers can create rich situational activities through music, video appreciation, and role playing. For example, when introducing the concept of emotion, teachers can use music works familiar to students. Different music represents different moods, guide students to experience their own emotional feelings, and then introduce the concept and categories of emotion. When explaining the "ABC theory of emotions", you can use the problem situation "Your good friend and you have an appointment, but he is late when the appointment time comes" to make students think about the possible reasons for being late and role play different reasons for being late in groups. The different reasons for being late will cause different emotional experiences for those who are waiting for others. At this point, let the students share different ideas, and the teacher will guide the comparison that different people have different emotional experiences for the same thing, leading to the concept of unreasonable beliefs and deepening students'understanding.

In participatory teaching, a "flipped classroom" approach can also be used to allow students to teach parts of the topic
[10]. The teacher can divide students into small groups, assign tasks, and instruct each group to search for information. Each group should create a coursework and assign a representative to finish the lesson within the limited time, while asking other students in the class to serve as judges to comment on it. Finally, the teacher summarizes and announces the results of each group. This kind of competition allows each student to participate in the study as a master, with high learning enthusiasm and good results. Of course, when letting students take the lead, the teacher should listen carefully and be able to find out which knowledge points are not taught properly or which important knowledge points are missed by the students, so as to check the gaps in time.

\section{Stage 5: Evaluation of the design process and results}

The evaluation stage requires that the designed evaluation criteria, evaluation plan, etc. must be fair and reasonable, evaluating all aspects of teaching objectives, student learning, teaching methods, etc., during and after the teaching is carried out.

At the end of the course, teachers should review whether the teaching content has been taught in the corresponding class hours, whether the pre-set teaching objectives have been achieved, and how effective the teaching is.

Teaching is an interactive process, and teachers should be evaluated not only on their teaching methods and content, but also from the perspective of students' learning activities [11]. The teacher of the class observes whether the students actively participate in the teaching and whether they have different emotional experiences with the teaching process through their expressions and states in the classroom learning. In the process of teacher-student communication, students are observed to see whether they are willing to cooperate and communicate with their classmates, whether they can take the initiative to think about problems, and whether they can ask valuable questions on their own. The teaching activities are evaluated in several aspects, including the students' participation in the classroom, their communication with classmates and the teacher, and their state of engagement in thinking [12].

Whether the teaching method is applied properly has a significant impact on the teaching effect. Teachers should pay attention to how well students participate and whether they achieve the intended effect when using teaching methods to judge whether the methods are properly chosen and used. Old teachers with rich teaching experience can be invited to observe and record in the classroom, and give feedback and suggestions after class, which will help teachers summarize experience and improve teaching methods.

\section{Stage 6: Reflection and Feedback}

The reflection and feedback stage is a holistic reflection done by teachers and students on their own performance in the whole teaching process after they carry out the evaluation and give feedback on their reflections. Reflect on the problems and shortcomings of the teaching process, as well as the progress made, to achieve self-improvement, mutual promotion and other results. It is important to be sincere when giving feedback on problems, taking care not to criticize or accuse, 
not to exaggerate or minimize the results of things. [13].

In the process of reflection, it is also necessary to consider how to connect subsequent courses. Participatory instructional design is not a one-off event. You should not only consider this instructional design, but also provide support for the next instructional design to achieve a virtuous circle. The latter instructional design should consolidate and deepen the results of the previous implementation.

\section{Problems That Should Be Noted in the Implementation of Participatory Teaching}

\subsection{Adopting the Small Class Teaching to Ensure Teaching Effect}

Participatory teaching requires the mobilization of students' enthusiasm and subjectivity, requiring classroom tables and chairs not to be fixed and can be placed at will, while multimedia equipment and mobile displaying boards should be available. The number of students is limited to 80 , grouped before class, with 8-10 students in each group. This will not only enhance effective communication among students, but also solve the problem of teachers' lack of attention to students.

\subsection{Effective Combination of Counseling Techniques and Teaching Tools}

The prerequisite for participatory teaching is to establish a relationship of equality, respect and understanding with students. We should flexibly use counseling techniques such as dialogue, communication and sincerity to create a warm and safe teaching environment, and appropriately use emotional simulation, case study, role play and behavioral training according to the teaching content and students' responses in class, so that students can experience a sense of subjectivity in the teaching process and actively participate in it, and then become aware of themselves and internalize mental health knowledge.

\subsection{Controlling the Atmosphere and Direction of the Classroom}

In the "flipped classroom", students may deviate from the syllabus and some of them may even play wildly, which requires teachers to take control of the whole situation and correct the deviation in time. Contradictions or conflicts may arise when students are involved in role-playing, scenario simulations, debates and other activities. Teachers must have sufficient ability to deal with these emergencies and guide students to think positively.

\section{Conclusion}

The concern for participatory teaching design is rooted in real-life teaching dilemmas that cannot be solved overnight, but the innovation of teaching methods is a permanent issue to be constantly studied in the teaching process [14]. For this reason, teachers and students must work together and participate together to turn the mental health education course, which integrates knowledge transfer, psychological experience and behavioral training, into a happy learning process with high student participation and good internalization effect [15].

\section{References}

[1] Paulo Freire, Myra Bergman Ramos. Pedagogy of the Oppressed [M]. Continuum Intl PubGroup, 2000. 9.

[2] Gaël Brulé, Ruut Veenhoven. Participatory Teaching and Happiness in Developed Nations [J]. Advances in Applied Sociology. Scientific Research Publishing. 2014: 235-245.

[3] Faulkner School of Media and Communication, Bowling Green State University, Bowling Green, USA) Watson School of Media and Communication, Bowling Green State University, Bowling Green, USA) Pollino School of Media and Communication, Bowling Green State University, Bowling Green, USA) Shetterly School of Media and Communication, Bowling Green State University, Bowling Green, USA). "Treat me like a person, rather than another number": university student perceptions of inclusive classroom practices $[\mathrm{J}]$. Communication Education, 2021, 70 (1): 92-111.

[4] Jia Zhao and Xuelin Chen and Lele Lian. Design and Application of Participatory Teaching in Biology Teaching in Secondary Vocational Schools-- Take "Beer Fermentation Engineering Experiment" as an Example [J]. International Journal of Social Science and Education Research, 2021, 4 (3).

[5] LI Jinghua. Application of Participatory Teaching Method in Mental Health Education Curriculum [J]. China Adult Education, 2007, 000 (023): 141-142.

[6] Deng Min, Chen Xu. Strengthening the Practice Research of College Students' Mental Health Education -- Comment on the Interaction Manual of College Students' Mental Health Education in Classroom [J]. Exploration of Higher Education, 2020 (1): 45.

[7] Wu Jie, Guo Benyu. Mental health education in colleges and universities based on evidence-based practice [J]. Heilongjiang Higher Education Research, 2020, 000 (004): 108-111.

[8] Wang Yang, Cao Yu, Zhao Zhigang, Zhang Yan, Qiu Huimin. The application of case-based teaching method in mental health education curriculum [J]. Chinese Journal of Medical Education, 2020, 40 (06): 439-442.

[9] Shi Fenfang, Liu Lei. An Analysis of Learning Psychology and Teaching in Flipped Classroom [J]. China Vocational and Technical Education, 2015, 000 (029): 21-25.

[10] Wang Ziwei, Li Fengzhan, Xiao Wei. Analysis of Teaching Structure Elements in Flipped Classroom [J]. Chinese Journal of Medical Education Exploration, 2018, 017 (009): P. 882-886.

[11] Chen Yukun. Educational evaluation [M]. People's Education Press, 2011: 43. 
[12] Cai Yaxuan, Shi Xiaoyan. A summary of the research on evaluation of teaching quality of university teachers $[\mathrm{J}]$. Journal of Baoding University (Natural Science Edition), 2011, 24 (01): 95-97.

[13] Ma Jianqing. An analysis of the gains and losses of ten years' research on the mental health of college students in China [J]. Chinese Journal of Mental Health, 1998 (01): 56-59.

[14] Li Yongfa, Tian Xiuhua. The landing strategy of participatory teaching mode in colleges and universities--Taking the teaching of "Marketing Science" as an example [J]. Journal of Agricultural University of Hebei (Agriculture and Forestry Education Edition), 2017, 19 (03): 5-8.

[15] Wang Yu. On the Practice and Application of SARAR Participatory Teaching Method in College Students' Mental Health Education Course [J]. Education and Teaching Forum, 2015 (01): 282-284. 